\title{
ERRATUM
}

\section{Erratum to: Ten concerns about blood pressure measurement and targets in paediatric sepsis}

Matko Marlais ${ }^{1}$, Mark D. Lyttle ${ }^{2}$ and David Inwald ${ }^{1 *}$

C 2017 Springer-Verlag Berlin Heidelberg and ESICM

\section{Erratum to: Intensive Care Med}

\subsection{7/s00134-016-4642-7}

The name and affiliation of the colleague thanked in the Acknowledgements were rendered incorrectly. The correct text is as follows:

\section{Acknowledgements}

We thank Dr. Stephen Marks, Department of Paediatric Nephrology, Great Ormond Street Hospital for Children NHS Foundation Trust, for his valued contribution.

\section{Author details}

${ }^{1}$ Paediatric Intensive Care Unit, St Mary's Hospital, Imperial College Healthcare NHS Trust, London W2 1 NY, UK. ${ }^{2}$ Faculty of Health and Life Sciences, University of the West of England, Bristol BS16 1DD, UK.

Published online: 31 January 2017

\footnotetext{
*Correspondence: d.inwald@imperial.ac.uk

1 Paediatric Intensive Care Unit, St Mary's Hospital, Imperial College

Healthcare NHS Trust, London W2 1NY, UK
}

Full author information is available at the end of the article

The online version of the original article can be found under doi:10.1007/s00134-016-4642-7.

\section{䈝 Springer}

